American Journal of Applied Sciences 9 (10): 1534-1537, 2012

ISSN 1546-9239

(C) 2012 Science Publication

\title{
Power-Voltage Characteristics of Power System with the Long Transmission Line
}

\author{
Prechanon Kumkratug \\ Department of Electrical Engineering, Faculty of Engineering at Si Racha, \\ Kasetsart University, 199 M.6, Tungsukhla, Si Racha, Chonburi, 20230, Thailand
}

\begin{abstract}
Problem statement: Power- Voltage curve provides very important information for voltage stability analysis. The exact long transmission line model consists of the resistance and the reactance. The resistance causes in the active line loss. It is not easy task to achieve the power-voltage curve characteristics of power system with the exact long line model. Approach: This study applies the concept of the Newton-Raphson method to iteratively solve the nonlinear power flow equations. The Power-Voltage (P-V) curve characteristic of the system without line loss and with line loss are plotted and compared on various cases. Results: It is found from the study that the resistance of the line obviously provides the negative effects on the voltage stability. The line loss causes in the decrement of the critical point. In addition, it is found that the leading power factor can increase the critical point of P-V curve. Conclusion: The exact long line model should be considered for voltage stability analysis of the system with the long transmission line.
\end{abstract}

Key words: Voltage stability, voltage collapse, critical voltage, critical power, power-voltage curve, newton-raphson, reactive power, active power

\section{INTRODUCTION}

Power system stability is classified as rotor angle stability and voltage stability. Voltage stability is a stability in power systems which are heavily loaded, disturbance or have a insufficiency of reactive power. Nowadays, the demand of electricity has dramatically increased and a modern power system becomes a complex network of transmission lines interconnecting the generating stations to the major loads points in the overall power system in order to support the high demand of consumers. It is becoming increasingly important to fully utilize the existing transmission system assets due to environmental legislation, rightsof-way issues and costs of construction and deregulation policies that introduced in recent years. A number of Flexible AC Transmission System (FACTS) controllers, based on the rapid development of power electronics technology, have been proposed for better utilization of the existing transmission systems (Omar et al., 2010; Al-Husban, 2009; Osuwa and Igwiro, 2010; Prechanon, 2010; Kumkratug, 2011; Zarate-Minano et al., 2010).

The evaluation of the Power-Voltage (P-V) curve of the power system is one of the most important research areas for power engineers because it indicates the maximum power load. If the load is increased beyond the maximum value, the voltage will be collapsed and then the system is considered as unstable.
The transmission line is one of the most important parts in power system components. Most of the fault occurs at the transmission line. It is generally divided into three major categories; medium, medium and long model whose distance are about $80 \mathrm{~km}$, above $80-250$ and above $250 \mathrm{~km}$, respectively. Many previous researches used simple transmission line model by neglecting its resistance or capacitance. To fully utilization the existing system, the exact transmission line should be further investigated.

This study investigated the effects of line loss in long transmission line on voltage stability. The mathematical model of the power flow is systematically derived. The concept of the Newton-Raphson method is applied to iteratively solve the nonlinear power flow equations. The Power-Voltage (P-V) curve characteristic of the system without line loss and with line loss are plotted, discussed and compared on various cases.

\section{MATERIALS AND METHODS}

Mathematical model: Consider the simple system with the lump of nominal $\pi$ model as shown in Fig. 1a. The generator supplies the active power and reactive power, which is transferred through a transmission line to the load. The voltage, active power and reactive power at load are represented by $V_{R}, P_{R}$ and $Q_{R}$, respectively. 


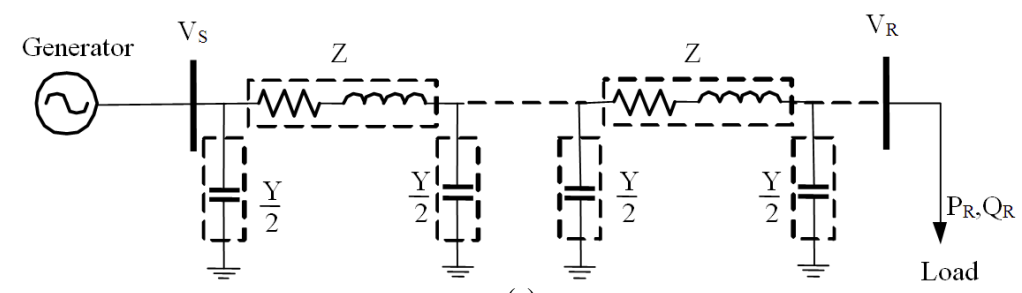

(a)

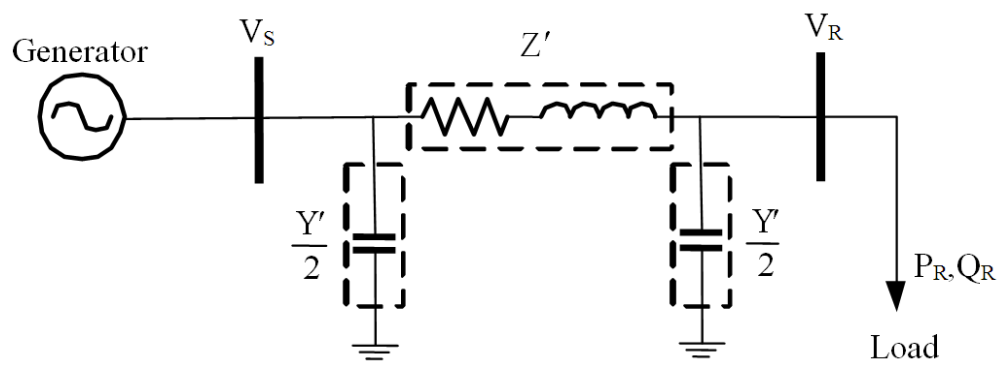

(b)

Fig. 1: Configuration of a power system with the long transmission line model for illustration of voltage instability (a) lump of nominal $\pi$ models (b) a equivalent $\pi$ model

The voltage at generator bus $\left(\mathrm{V}_{\mathrm{S}}\right)$ is considered as constant value. The lump of the nominal $\pi$ model is represented by a equivalent $\pi$ model as shown in Fig. $1 b$.

The equivalent Z'is given by Eq. 1:

$\mathrm{Z}^{\prime}=\mathrm{Z}_{\mathrm{c}} \sinh \gamma 1$

The equivalent $\mathrm{Y}^{\prime}$ is given by Eq. 2:

$\mathbf{Y}^{\prime}=\frac{2}{\mathbf{Z}_{\mathrm{c}}} \sinh \frac{\gamma \mathrm{l}}{2}$

Here the $\gamma$ and $Z_{c} n$ Eq. 1 and 2 are given by Eq. 3:

$$
\gamma=\sqrt{\mathrm{ZY}} / 1
$$

And:

$$
\mathrm{Z}_{\mathrm{c}}=\sqrt{\frac{\mathrm{Z}}{\mathrm{Y}}}
$$

The constant $\gamma$ in Eq. 30 and $Z_{c}$ are in Eq. 4 the propagation constant and characteristic constant of the long transmission line, respectively. This study applies the concepts of the two ports network to derive power flow at load as given by:

$\mathrm{A}=\left(1+\mathrm{Y}^{\prime} \mathrm{Z}^{\prime} / 2\right)$

$$
\begin{aligned}
& \mathrm{B}=\mathrm{Z}^{\prime} \\
& \mathrm{C}=\mathrm{Y}^{\prime}\left(1+\mathrm{Y}^{\prime} \mathrm{Z}^{\prime} / 4\right) \\
& \mathrm{D}=\mathrm{A}
\end{aligned}
$$

From Eq. 5-8, the voltage and the current at load bus $\left(\mathrm{V}_{\mathrm{R}}, \mathrm{I}_{\mathrm{R}}\right)$ can be expressed in terms of matrix by

$$
\left[\begin{array}{c}
\mathrm{V}_{\mathrm{R}} \\
\mathrm{I}_{\mathrm{R}}
\end{array}\right]=\left[\begin{array}{cc}
\mathrm{D} & -\mathrm{B} \\
-\mathrm{C} & \mathrm{A}
\end{array}\right]\left[\begin{array}{l}
\mathrm{V}_{\mathrm{S}} \\
\mathrm{I}_{\mathrm{S}}
\end{array}\right]
$$

From Eq. 9, the line current at load bus is given by:

$I_{R}=\frac{V_{S}-A V_{B}}{B}=\frac{V_{S} \angle\left(\delta-\theta_{B}\right)}{B}-\frac{A V_{R}}{B} \angle\left(\theta_{A}-\theta_{B}\right)$

From Eq. 10, the complex power load is written by:

$$
\begin{aligned}
& S_{R}=P_{R}+j Q_{R}=V_{R} I_{R}^{*} \\
& =\frac{V_{R} V_{S}}{B} \angle\left(\theta_{B}-\delta\right)-\frac{A V_{R}^{2}}{B} \angle\left(\theta_{B}-\theta_{A}\right)
\end{aligned}
$$
Eq. 11:

Then the active and reactive power load are given by

$P_{R}=\frac{V_{R} V_{S}}{B} \cos \left(\theta_{B}-\delta\right)-\frac{A V_{R}^{2}}{B} \cos \left(\theta_{B}-\theta_{A}\right)$

And:

$\mathrm{Q}_{\mathrm{R}}=\frac{\mathrm{V}_{\mathrm{R}} \mathrm{V}_{\mathrm{S}}}{\mathrm{B}} \sin \left(\theta_{\mathrm{B}}-\delta\right)-\frac{\mathrm{AV}_{\mathrm{R}}^{2}}{\mathrm{~B}} \sin \left(\theta_{\mathrm{B}}-\theta_{\mathrm{A}}\right)$ 
Am. J. Applied Sci., 9 (10): 1534-1537, 2012

The objective of this study is to evaluate the voltage at load bus $\left(\mathrm{V}_{\mathrm{R}}\right)$ with various cases of load. This study applies the Newton-Raphson method to iteratively solve the nonlinear Eq. 12 and 13 given by:

$\left[\begin{array}{c}\Delta \mathrm{P}_{\mathrm{R}} \\ \Delta \mathrm{Q}_{\mathrm{R}}\end{array}\right]=\left[\begin{array}{ll}\frac{\partial \mathrm{P}_{\mathrm{R}}}{\partial \delta} & \frac{\partial \mathrm{P}_{\mathrm{R}}}{\partial \mathrm{V}_{\mathrm{R}}} \\ \frac{\partial \mathrm{Q}_{\mathrm{R}}}{\partial \delta} & \frac{\partial \mathrm{Q}_{\mathrm{R}}}{\partial \mathrm{V}_{\mathrm{R}}}\end{array}\right]\left[\begin{array}{c}\Delta \delta \\ \Delta \mathrm{V}\end{array}\right]$

The general form of (14) is given by Eq. 15-17:

$$
\left[\begin{array}{l}
\Delta \mathrm{P}_{\mathrm{R}} \\
\Delta \mathrm{Q}_{\mathrm{R}}
\end{array}\right]=\left[\begin{array}{ll}
\mathrm{J}_{1} & \mathrm{~J}_{2} \\
\mathrm{~J}_{3} & \mathrm{~J}_{4}
\end{array}\right]\left[\begin{array}{l}
\Delta \delta \\
\Delta \mathrm{V}
\end{array}\right]
$$

Here:

$$
\mathrm{J}_{1}=\frac{\partial \mathrm{P}_{\mathrm{R}}}{\partial \delta}
$$

$\mathrm{J}_{2}=\frac{\partial \mathrm{P}_{\mathrm{R}}}{\partial \mathrm{V}}$

$\mathrm{J}_{3}=\frac{\partial \mathrm{Q}_{\mathrm{R}}}{\partial \delta}$

$\mathrm{J}_{4}=\frac{\partial \mathrm{Q}_{\mathrm{R}}}{\partial \mathrm{V}}$

\section{RESULTS}

The proposed method is tested on the sample system as shown in Fig. 1. The system supplies power which is transferred through a $250 \mathrm{~km}$ transmission line to the load. The system voltage at the generator bus is $500 \mathrm{kV}$. Fig. 2 shows the P-V curve of the system with the long transmission line for various cases of power factor. Table 1 summarizes the critical point $\left(V_{R}^{\text {cr }}, P_{R}^{c r}\right)$ of Fig. 2.

\section{DISCUSSION}

It can be seen from the Fig. 2 that without load or light load, the voltage at load is beyoud nominal voltage $500 \mathrm{kV}$ because the effect of the shunt line charging. The lagging load provides the negative effects on the voltage stability. As can be seen from the Figure that the lagging load is increased, the voltage at load significantly decreases whereas with the leading power factor, the voltage stability is much better.
Table 1: The critical point of the system with long transmission line for various power factors

\begin{tabular}{lccc}
\hline & & Critical point & \\
Case & $\tan \phi$ & $\mathrm{P}_{\mathrm{R}}^{\mathrm{cr}}(\mathrm{W})$ & $\mathrm{V}_{\mathrm{R}}^{\mathrm{cr}}(\mathrm{kV})$ \\
\hline 1 & 0.4 & 835.81 & 307.04 \\
2 & 0.2 & 996.12 & 325.85 \\
3 & 0.0 & 1191.17 & 352.28 \\
4 & -0.2 & 1418.57 & 388.73 \\
5 & -0.4 & 1670.80 & 433.29 \\
\hline
\end{tabular}

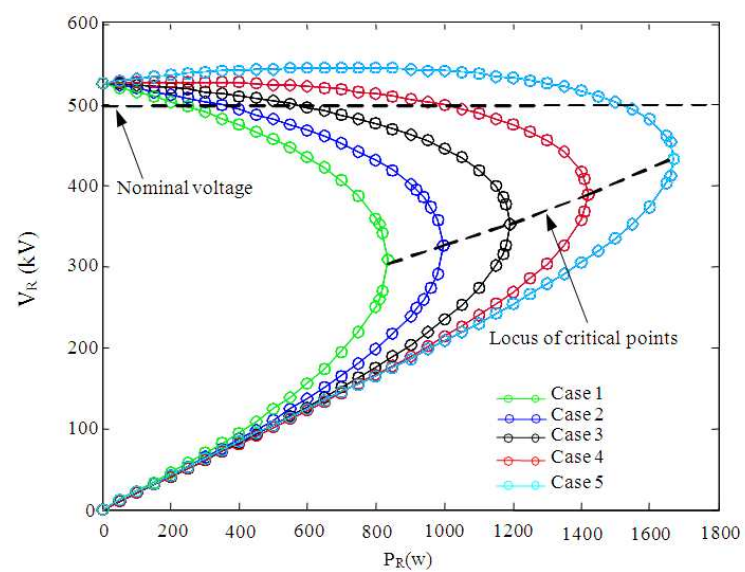

Fig. 2: P-V curve of the sample system with long transmission line for various power factors

The critical point $\left(\mathrm{P}_{\mathrm{R}}^{\mathrm{cr}}, \mathrm{V}_{\mathrm{R}}^{\mathrm{cr}}\right)$ of load in unity power factor is at the point $(1191 \mathrm{~W}, 352 \mathrm{kV})$. The lagging load causes in decreasing of the critical point. With tan $\phi=0.4$, the critical point is decreased to the point (835.81, 307.04). The critical point can be improved by increasing the leading load. With $\tan \phi=0.4$, the critical point is increased to the point $(1670,433)$.

\section{CONCLUSION}

This study systematically derives mathematical model of power system with the exact long transmission line model for voltage stability analysis. The concept of the two ports network is applied to obtain power flow equation and then the NewtonRaphson iterative method is used to solve the nonlinear equations. The Power-Voltage (P-V) curve characteristic of the system with various cases are plotted and compared.

It was found from the study that the line charging causes in the over voltage beyond nominal voltage and The leading power factor of load can improve voltage stability and the critical point of power system whereas the lagging load provides the negative effect on voltage stability and decreases the critical point. 


\section{REFERENCES}

Omar, R., N.A. Rahim and M. Sulaiman, 2010. New control technique applied in dynamic voltage restorer for voltage sag mitigation. Am. J. Eng. Applied Sci., 3: $\quad 42-48 . \quad$ DOI: 10.3844/ajeassp.2010.42.48

Al-Husban, A.N., 2009. An eigenstructure assignment for a static synchronous compensator. Am. J. Eng. Applied Sci., 2: $\quad 812-816 . \quad$ DOI: 10.3844/ajeassp.2009.812.816

Osuwa, J.C. and E.C. Igwiro, 2010. Uninterruptible power supply using solar rechargeable battery. Physics. Int., 1: 77-82. DOI: 10.3844/pisp.2010.77.82
Prechanon, K., 2010. Coordination of series and shunt flexible alternating current transmission line system devices based thyristor controller for improving power system stability. Am. J. Applied Sci., $\quad 8$ : $\quad 355-358 . \quad$ DOI: 10.3844/ajassp.2011.355.358

Kumkratug, P., 2011. Optimal control design of static synchronous series compensator for damping power system oscillation. J. Soc. Sci., 7: 844-848. DOI: $10.3844 /$ jcssp.2011.844.848

Zarate-Minano, R., T. Van Custsem, F. Milano and A.J. Conejo, 2010. Sexuring transient stability using time domain simulations within an optimal power flow. IEEE Trans. Power Syst., 5: 243-253. DOI: 10.1109/TPWRS.2009.203069 